\title{
Successfully developing advanced practitioner roles: policy and practice mechanisms
}

\author{
Tara Officer and Jackie Cumming \\ Health Services Research Centre, Victoria University of Wellington, \\ Wellington, New Zealand, and \\ Karen McBride-Henry \\ Graduate School of Nursing, Midwifery and Health, \\ Victoria University of Wellington, Wellington, New Zealand
}

\begin{abstract}
Purpose - The purpose of this paper is to lay out how advanced practitioner development occurs in New Zealand primary health care settings. The paper specifically focuses on mechanisms occurring across policy creation and in practice leading to successful role development.

Design/methodology/approach - The authors applied a realist approach involving interviews, document review and field log observations to create refined theories explaining how successful development occurs. Findings - Three final mechanisms were found to influence successful advanced practitioner role development: engagement in planning and integrating roles; establishing opportunities as part of a well-defined career pathway; and championing role uptake and work to full scopes of practice.

Research limitations/implications - This research focuses on one snapshot in time only; it illustrates the importance of actively managing health workforce change. Future investigations should involve the continued and systematic evaluation of advanced practitioner development.

Practical implications - The successful development of advanced practitioner roles in a complex system necessitates recognising how to trigger mechanisms occurring at times well beyond their introduction.

Social implications - Potential candidates for new roles should expect roadblocks in their development journey. Successfully situating these roles into practice through having a sustainable and stable workforce supply provides patients with access to a wider range of services.

Originality/value - This is the first time a realist evaluation has been undertaken, in New Zealand, of similar programmes operating across multiple sites. The paper brings insights into the process of developing new health programmes within an already established system.
\end{abstract}

Keywords Workforce, Realist evaluation, Non-medical prescribing, Nurse practitioner, Pharmacist prescriber Paper type Research paper

\section{Introduction}

New Zealand-based advanced practitioners (nurse practitioners and pharmacist prescribers) are independent prescribers, defined in the academic literature as those able to prescribe fully autonomously within their area of competence (Emmerton et al., 2005). Globally, there is increasing acceptance and interest in advanced practitioner roles. These roles create opportunities to advance better health care delivery through nursing and pharmacy professions and facilitate changes in workforce resource allocation. Benefits emerging from their use include improved health service accessibility (Martin-Misener et al., 2009; Bissell et al., 2008), improved overall patient experience (Latter et al., 2011) and better quality of care (Horrocks et al., 2002).

The authors thank all 84 interviewees who participated in this research. The authors also wish to acknowledge Nurse Practitioners New Zealand, the Clinical Advisory Pharmacists Association and the Pharmaceutical Society of New Zealand for facilitating contact with nurse practitioners and pharmacist prescribers.

Developing advanced practitioner roles

Received 26 February 2018 Revised 1 May 2018 Accepted 2 October 2018 
JHOM

33,1

The New Zealand Government saw the introduction of nurse practitioners as a means of improving patient choice of health provider, and improving access to care within high-risk populations, such as low socioeconomic status and rural communities (Hughes and Carryer, 2002). Pharmacist prescribers were introduced to improve medicines management, and support medical doctors (Pharmacy Council of New Zealand, 2010). Furthermore, acting as nurse practitioners and pharmacist prescribers may facilitate the use of advanced practice skills in nursing and pharmacy.

Since its inception in 2001, over 3,000 nurses have completed New Zealand postgraduate training to reach nurse practitioner education levels (Thomas, 2017); however, in 2017 only 242 nurse practitioners were registered and practising in New Zealand (Nursing Council of New Zealand, 2017a). Similarly, the New Zealand Ministry of Health stated that they expected approximately 20 pharmacists to obtain pharmacist prescriber status annually following the 2013 introduction of new regulations allowing these roles (Ministry of Health, 2012). In 2014, no new individuals enrolled in pharmacist prescriber training (Piper, 2014), bringing in doubt the future of the course. As of August 2016, only 18 pharmacists are registered in the pharmacist prescriber scope of practice (Ministry of Health, 2017).

While many frameworks exist describing the process of implementing advanced practitioner (specifically advanced nursing) roles (Bryant-Lukosius and DiCenso, 2004), managing skill mix (Sibbald et al., 2004) or revising health professional roles (Laurant et al., 2009; De Geest et al., 2008), only one was found describing the process of advanced practice nurse policy and practice development. Schober et al. (2016) studied the development of advanced practice nursing positions in Singapore between 2008 and 2012. Their study resulted in a conceptual policy framework to guide coordinated advanced practice nurse policy development and implementation. The framework identifies critical points necessary for successful role development. These occur at junctures of policy development and role implementation that are dependent on the sphere of influence of various groups. Schober et al. (2016) emphasised that although constructive policy supporting advanced nursing is crucial to its success, there remains little literature demonstrating the ways in which relevant policy processes formed these roles. A better understanding of how policy action evolves into practice will facilitate improved future implementation of these roles.

The New Zealand health care and policy environments hold challenges for the introduction of new roles. To support a change in health workforce redesign understanding how these roles form across complex health care delivery systems should allow improved policy development and implementation. This, in turn, will facilitate the improved use of health workforce resources, enabling health professionals to work to the full extent of their competence and scopes of practice. This paper describes the results of an evaluation of nurse practitioner and pharmacist prescriber role development in New Zealand primary health care. Its specific focus is on factors (mechanisms) present in both policy and practice that influence the success of developing these roles.

\section{Methodology}

The evaluation used a realist approach, employing a qualitative research design. Realist appraisals of programmes question, within contextual constraints, how programmes achieve outcomes. When viewing causal pathways from a realist perspective, a generative logic of causality applies where contexts "trigger" (cause to have effect, turn on, modify) underlying causal mechanisms, thereby explaining outcomes (Pawson et al., 2004, 2005; Wong et al., 2013; Pawson and Tilley, 1997; Vaessen and Leeuw, 2011). Context can include features such as infrastructure, institutions and interpersonal relationships, and may also be specific to individuals (Pawson, 2006). Context-mechanism-outcome (CMO) configurations provide the causal connections explaining how programmes operate (Pawson, 2006). The generative logic sees outcome patterns forming when, due to contexts, different 
mechanisms trigger, or fail to trigger. These CMO configurations can allow programme targeting to specific contexts to meet policy objectives (Pawson and Tilley, 2004).

Realist approaches explicitly focus on the iterative and cumulative testing and refinement of theories (also referred to as middle-range theories; Merton (2007)), with generative mechanisms establishing causal relationships (Blamey and Mackenzie, 2007). Realist research works under the principle that stakeholders contribute diverse perspectives because of their roles in a programme (Pawson and Tilley, 1997; Pawson, 1996). In the case of this study, nurse practitioner and pharmacist prescriber development is subject to the reasoning, choices and resources of those likely to use, and affect change in, these programmes.

Realist approaches, by working at the level of theories, tend to be applicable to interventions sharing similar traits across organisational boundaries (Pawson and Tilley, 2004). Making best use of health professionals requires knowing how to form these roles appropriately, and then how to use them synergistically. Evaluating both nurse practitioner and pharmacist prescriber roles together strengthens the middle-range theories formed in this research. In studying the development of both nurse practitioner and pharmacist prescriber roles in New Zealand primary health care, this study in effect considers two programmes with a common "family resemblance" that operate across many settings; that is, they have similar underlying characteristics explaining how they change (Pawson, 2002, 2006). These practitioners have similar registration requirements that include a set number of years of relevant postgraduate experience, and completion of postgraduate training. Nursing and pharmacy professions are also generalists by training. Likewise, both nurse practitioners and pharmacist prescribers have expanded their original practice base through learning traditionally medically dominated skills. The intended outcomes of implementing these roles, improved health care quality and accessibility, are also alike. This study builds on past evaluations; in researching the development of both nurse practitioner and pharmacist prescriber roles, it allows comparisons to be made between a more recently created programme (pharmacist prescribers), and a more established one (nurse practitioners). As such, this research identifies commonalities and further refines theories of advanced practitioner role development. From this, more certainty exists that the generated middle-range theories hold true across different programmes.

In this study, the key outcome of interest is an intermediate outcome, involving the effective development of advanced practitioner roles, with nurse practitioners and pharmacist prescribers successfully and sustainably delivering services at the top of their scope of practice (Figure 2). Contexts and mechanisms influence role development and the ability to "complete" various stages of this process. Where development is successful, advanced practitioners may deliver on the intended final outcomes of their roles (delivering safe, quality and timely care to patients).

\section{Methods}

Realist approaches are method-neutral or pluralist (Pawson and Tilley, 2001). This study uses a variety of qualitative methods to refine a picture of advanced practitioner development. These methods included semi-structured interviews, document review and field logs.

\section{Data collection}

This research initially involved a synthesis $\left(\alpha_{1}\right.$, Figure 1$)$ of existing literature to generate initial middle-range theories. These theories acted as a backdrop against which to position this study, through the creation of an initial theoretical framework. We then assessed advanced practitioner formation in New Zealand primary health care $\left(\alpha_{2}\right)$ using interviews, document review and field logs that collectively offered the ability to verify results, thereby, supporting internal validity. Following data analysis, data interpretation $\left(\alpha_{3}\right)$ permitted revision of middle-range theories.
Developing advanced practitioner roles 


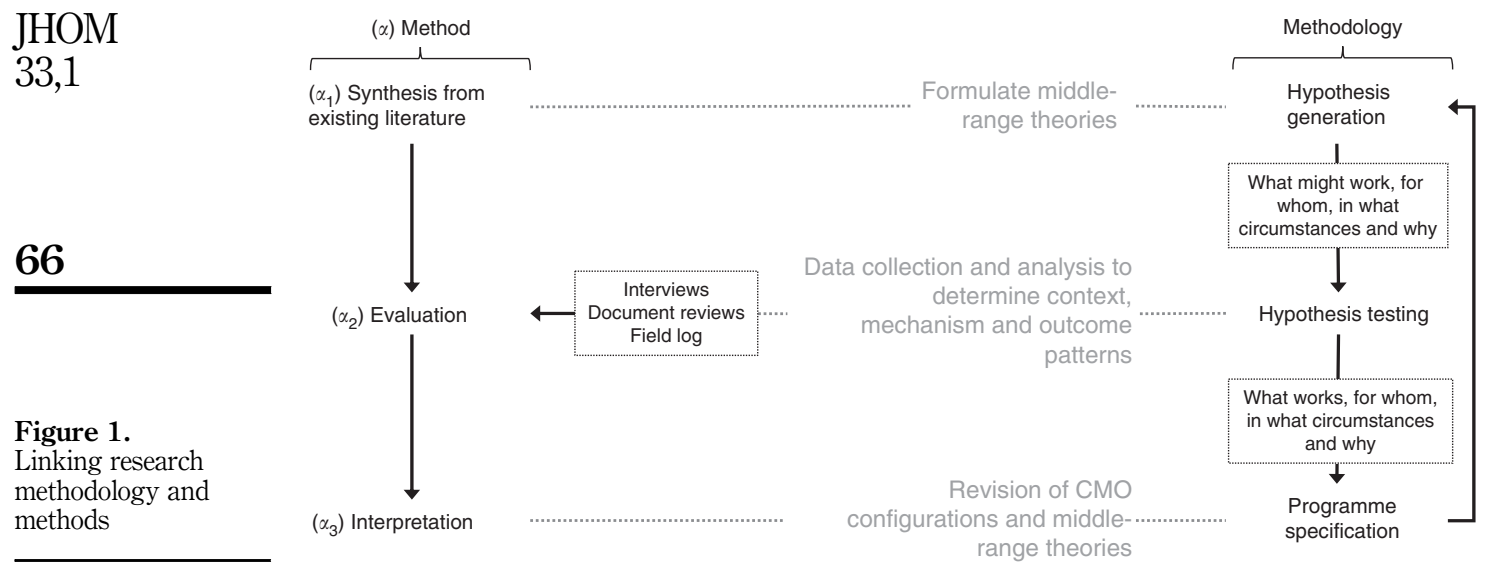

Interviews emerged as the best data collection method to capture stakeholder opinions. In addition to document review and field log observations, this study consisted of two rounds of qualitative semi-structured face-to-face interviews between December 2015 and October 2016. Individuals from training, policy, regulatory and union sectors (TPA) participated in the first round of interviews. Manzano (2016) suggested that interviewing individuals in these areas is appropriate for bringing together initial theories. Furthermore, these interviews offered a point around which $\mathrm{CMO}$ configurations could take shape and be further refined in subsequent interview rounds.

The second round of nationwide data collection involved interviews with nurse practitioners, pharmacist prescribers, general practitioners, patients or, in the case of individuals unable to give consent, with individuals responsible for their care. Individuals interviewed in this round operated at various points along the continuum of advanced practitioner formation - from initial employment and collaborative working arrangements to delivering and receiving care. This follows the approach of Manzano (2016), who noted that interviewing "frontline practitioners", such as nurse practitioners, pharmacist prescribers and general practitioners, offers insights into programme constraints and facilitators from different perspectives following top-down programme implementation. In contrast, patients and carers are more likely to be sensitised to outcomes of the advanced practitioner development process. Although Manzano (2016) identified that, to build middle-range theories, patients should be interviewed separately from other groups, in this research, budget constraints in most cases prevented repeat visits to New Zealand regions.

The value of two interview rounds lay in being able to test and refine emergent middle-range theories. Interviewing a purposively selected population, selected based on their knowledge of the programmes under study and via snowball sampling, created an information-rich sample (Patton, 2002). Participants either possessed specific knowledge of the advanced practitioner development process from a policy point of view, or they "lived" the development process (advanced practitioners, patients and other health professionals). These groups provided a theoretically informed sample, able to offer knowledge of different $\mathrm{CMO}$ configuration components. Most interviews concluded after approximately one hour when participants indicated that they had no further information to provide.

Advanced practitioners were contacted via third-party professional membership organisations. Each organisation agreed to send an invitation and information sheet describing the research to their member nurse practitioners or pharmacist prescribers. Having facilitated initial contact, advanced practitioners then contacted the primary researcher to indicate their willingness to participate. 
Advanced practitioners, following set criteria, selected a general practitioner to participate in this study. General practitioners approached for this research had experience working with nurse practitioners or pharmacist prescribers. Advanced practitioners preferentially selected a general practitioner with whom they had the most contact either in their current practice, or in a recent past workplace. If these doctors were unwilling or unable to participate, the advanced practitioner then selected another general practitioner who provided the advanced practitioner with peer review. Having received the general practitioner's initial consent, we then contacted them, confirmed their participation and arranged an appropriate interview time.

Advanced practitioners helped recruit patients for this research. These practitioners determined whether their patients were sufficiently medically fit to give informed consent and to undertake a face-to-face interview. Patient participants were all current patients of advanced practitioners and not acutely ill or facing extenuating family circumstances. Where patients were under 18 years old or otherwise unable to consent to participate in this study, then their parent, guardian or other carer was instead asked to participate in this research. Recruitment involved the random selection of up to four patients fitting these set criteria. Advanced practitioners then supplied patients or carers with a letter inviting them to contact the primary researcher, an information sheet describing this study, and a consent form. When potential interviewees made initial contact, we confirmed their understanding of the research and agreed an interview time.

Table I provides a breakdown of numbers participating in each interview cohort.

\section{Ethical considerations}

The Victoria University of Wellington Central Human Ethics Committee granted ethical approval for this project on 2 December 2015 (approval number 22388).

\section{Data analysis}

Data analysis commenced concurrently with interviews. Using the qualitative research software, NVivo 11 Pro (QSR International), interview transcripts and documents for review were stored and their contents coded consistently. An initial synthesis of literature surrounding nurse practitioner and pharmacist prescriber role change in primary health care created a basis against which to formulate a priori CMO configurations and middle-range theories. Following a realist approach, data analysis used these configurations as the primary imaging/coding structure (Marchal et al., 2012; Pawson, 2013). Data were first compared to the research questions to identify relevant responses. Building on initial configurations, using TPA interviewee data we then identified further refined CMO configurations. Coding went through several checks and iterations resulting in preliminary $\mathrm{CMO}$ configurations and a refined framework. We then systematically applied this framework to transcripts and documents for review, adding additional codes as they emerged from the data. Each round of analysis, corresponding to the introduction of data from different stakeholders and documents, led to more refined theories and data triangulation. Constant comparison of transcripts ensured testing and refinement of

\begin{tabular}{lcc}
\hline Participants & Potential participants & Participating \\
\hline Policy and training interviewees & 31 & 23 \\
Nurse practitioners & 20 & 16 \\
Pharmacist prescribers & 10 & 9 \\
General practitioners & 17 & 15 \\
Patients and carers & 28 (these individuals chose to contact the researchers) & 21
\end{tabular}

Developing advanced practitioner roles 
JHOM 33,1

Figure 2.

Influences on the successful development of advanced practitioner roles

theories, and facilitated our recognition of differences between data sharing similar codes. This, in turn, allowed grouping of data coded to similar concepts.

Having analysed data from interviews, documents for review and field logs, the next round of analysis aimed to generalise information from the specifics of individual cases to middle-range theories (Byng et al., 2005). To do this, we ascertained how mechanisms operating across cases resulted in different outcomes owing to the influence of context. It was then possible to make inferences about generative causality attributed to different contexts. The last analysis round aimed to generalise theories from different parts of the advanced practitioner development process to form a middle-range theory useful to policy and practice audiences and relevant to both nurse practitioner and pharmacist prescriber programmes.

In total, the analysis step transitioned from policy interviewee informed initial CMO configurations, to configurations informed by in-practice advanced practitioner development. It then transitioned to comparative analysis and more refined middle-range theory.

\section{Results}

Interviewees were mainly supportive of the development of nurse practitioner and pharmacist prescriber roles. However, emerging from interviewee narratives, we identified multiple structural constraints affecting the development process (Figure 2). Efforts to create advanced practitioner roles, for example, were constrained by funding decisions across the wider health sector that resulted in decisions not to fund training for pharmacist prescribers. Lack of recognition of advanced practitioner roles, variability in education and failure of legislative change to keep pace with policy and practice decisions are all contexts that impaired effective role development. While interviewees rarely solely discussed constraints to advanced practitioner development, it is likely that individuals who were unsuccessful in becoming nurse practitioners or pharmacist prescribers saw these contextual constraints as huge challenges.

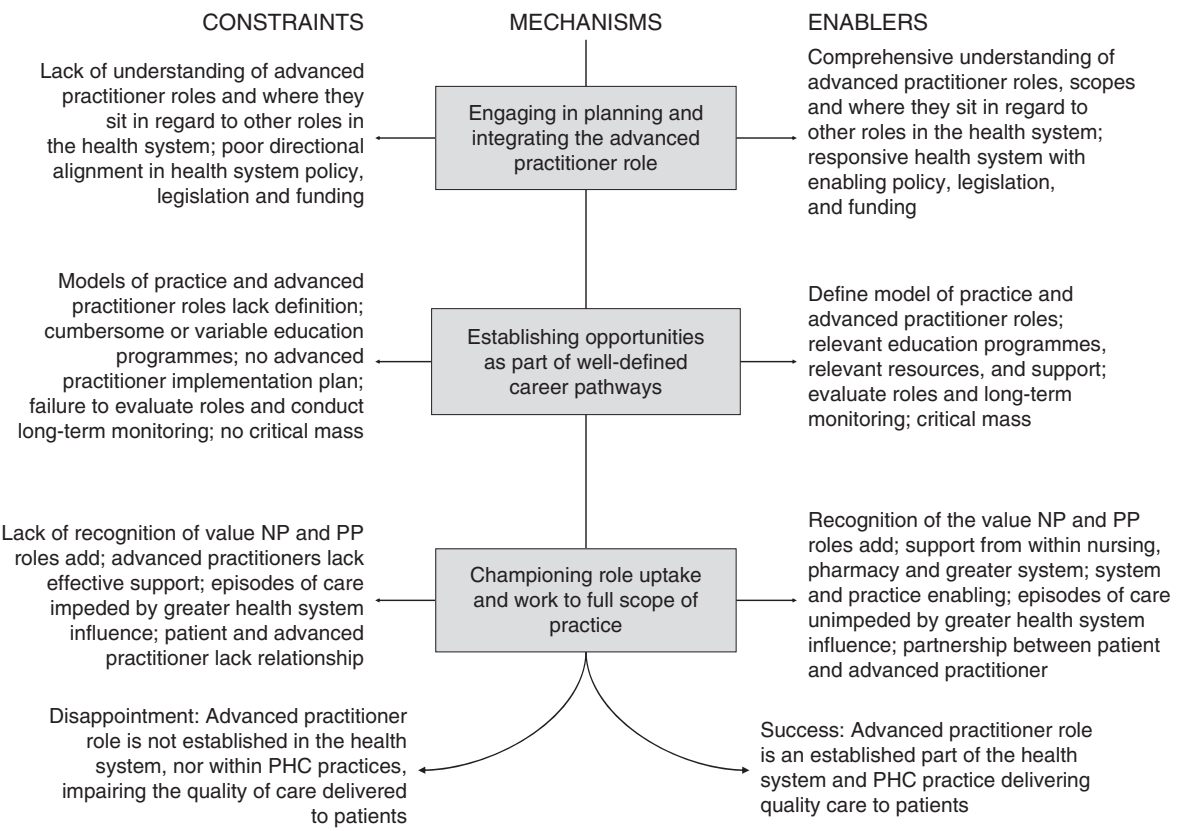


Loosely reflecting population distributions, the most common regions that interviewed advanced practitioners operated in were Auckland, Waikato, Wellington (North Island) and Canterbury (South Island). Several individuals operated in multiple locations within a region. Nurse practitioners and pharmacist prescribers generally worked in rural or low socioeconomic status areas. Similarly, advanced practitioners operated in a variety of roles, not all of which used their advanced practice skills. This was particularly common amongst pharmacist prescribers who often worked only part-time in advanced practice roles. Nurse practitioners and pharmacist prescribers often worked in multiple locations. Workplaces with advanced practitioners ranged from large integrated health centres to solepractitioner organisations.

This realist study identified many CMO configurations that appeared to explain aspects of advanced practitioner development. These will be explored in full in later papers. The focus of this paper is on those mechanisms operating across both policy and practice. These mechanisms are at the centre of Figure 2 and are presented below through three key themes: engagement in planning and integrating roles; establishing opportunities as part of a well-defined career pathway; and championing role uptake and work to full scopes of practice.

\section{Mechanism 1: engagement in planning and integrating roles}

Successful advanced practitioner development in both policy and practice requires engagement in planning and integrating advanced practitioner roles. The need to manage health workforce direction, boundaries of practice, logistics and funding were recurring themes amongst interview participants. Interviewees advised that in general continued engagement across policy and practice did not occur:

Policy changes $[\ldots]$ often fail $[\ldots]$ because the organisational culture hasn't changed. It's sort of top-down, they've changed the policy but underneath it, nothing's been done to make it happen [...] It's the same issues with [...] pharmacist prescribing. - TPA17

Introducing these roles into the health system offers the potential for work stream redesign. In such instances, successful role development requires aligning organisational culture with individual skills. In this research, interviewees questioned whether primary health care environments as they currently operate were amenable to advanced practitioners operating in roles reflecting their original intent. These interviewees suggested that nurse practitioners and pharmacist prescribers instead acted as substitutes for medical doctors:

The current model of general practice is so resistant to change that there's a danger that nurse practitioners will be sucked into practising like general practitioners [...] When you're faced with a room full of people who've all got desperately necessary acute presenting needs, it's hard to stay thinking the way you've been trained [...] If nurse practitioners simply start replacing GPs in general practice, we may not see the kinds of transformations that are inherent in the role. - TPA3

In a number of cases, individuals identified that engaging in planning and integrating nurse practitioner and pharmacist prescriber roles did not occur. Individuals suggested that reasons behind this included a lack of responsibility for engaging in planning by others in the workplace, and a reticence to realign the roles of others in the practice environment:

It was difficult to begin with, and that's probably something I should have done in hindsight, is explain the role [...] Initially, they thought some sort of glorified nurse but what they didn't appreciate was that eventually [the nurse practitioner] would be able to practise at this sort of level. - General practitioner 9
Developing advanced practitioner roles 
JHOM

33,1

70

\section{Mechanism 2: establishing opportunities as part of a well-defined career pathway}

A key requirement of successfully developing advanced practitioner roles is triggering the mechanism of establishing opportunities for nurse practitioners and pharmacist prescribers as part of well-defined career pathways. Most individuals failed to describe a systematic and coordinated approach to triggering this mechanism. Consequently, the ability to establish advanced practitioner roles in the health system met with variable success. In our interviews, when considering the nurse practitioner pathway, participants indicated that, until recently, the pathway nurse practitioner candidates followed to achieve expanded practice was ad hoc:

Their route to nurse practitioner is very varied depending on your background, whereas everybody who's a GP or other doctor, you've been to a medical school somewhere and there are similarities in your training $[\ldots]$ Whereas the nurse practitioner role, depending on where they were, their route [varied]. - General practitioner 9

Participants anticipated that as the effort to change nurse practitioner education and scopes of practice, and to open prescribing to more registered nurses (Nursing Council of New Zealand, 2017b) unfolded, the development process would become more streamlined. In turn, this would trigger establishment of opportunities for nurse practitioners.

Advanced practitioner role development requires an education system able to meet health system needs. The New Zealand pharmacist prescriber programme aimed to provide a solid foundation in prescribing within a defined area of practice. However, several participants noted that this foundation might poorly meet practice requirements:

The limitations on the prescribing meant that I didn't fit in the field that I wanted to go down, but it did provide a really good base to be a safe prescriber, to be able to make decisions in that smaller area. It gave you the skills to understand what was required for decision-making, to be able to develop other areas and scopes of practice. - Pharmacist prescriber 4

At different stages of training and continuing education, advanced practitioners and general practitioners commented on the availability of training opportunities and the fit with pharmacist and nursing skills. Advanced practitioners generally commented on a lack of access to relevant and timely training:

People were patch protecting. Family Planning was one. We had wanted to be able to insert IUCDs but [... they said no the training is for GPs and that's all we're funded for. Could I pay for it myself? No, we don't want nurse practitioners doing that. - Nurse practitioner 2

Many respondents questioned the fit of postgraduate advanced practice training with undergraduate pathways. Since its introduction in the early 2000s, nurse practitioner training has gone through many iterations. Participants perceived that nurse practitioner training pathways were becoming more streamlined and beginning to prepare nurses for advanced practice. The same could not be said for the pharmacist prescriber programme, which some participants indicated did not fit with the current direction of undergraduate training. This could in part be due to the relative newness of the latter's training, the smaller numbers of candidates and a lack of support from within the pharmacy profession:

The underpinning training that a BPharm gives pharmacists [...] doesn't necessarily lead on well to being a prescriber $[\ldots]$ because there's core skills and knowledge that prescribers need that isn't taught well in the BPharm and postgraduate work. - TPA17

\section{Mechanism 3: championing role uptake and work to full scopes of practice}

A third mechanism of importance in successfully developing advanced practitioner roles was championing role uptake and work to full scopes of practice. Individuals involved in championing these roles often included policy and training advocates, advanced 
practitioners and general practitioners. Interviewees often identified the importance of specific individuals in championing the advanced practitioner role or training pathway:

Nurse practitioners were very new and there were no real pathways [or] guidelines [...] I carried on with the master's [...] it took a number of years, and then started thinking well maybe I could be a nurse practitioner. I had a good nurse manager, and even the practice manager, they were supportive and went in to bat for me, working out a pathway, a way it could work here. - Nurse practitioner 11

On the other hand, pharmacist prescribers and nurse practitioners noted instances in which they were unable to operate to their full scope of practice. Respondents gave examples of where they lacked clinical champions, or lacked an environment where they were able to champion their own role:

I'm doing what I've always done. So there's no additional - there's been no acknowledgement or anything regarding that [...] Yeah, now I do a bit more [...] That has always been the case - "this will be great if you do this; oh, could you do this as well and could you do this?" Unfortunately, there's not ever any money because of our political environment, the DHB doesn't offer more. Pharmacist prescriber 9

Patient-health provider relationships played a part in championing work to full scopes of practice. Patients commonly identified differences between the services offered by a general practitioner, and those offered by their nurse practitioner or pharmacist prescriber. In identifying these differences, patients also pointed out their reasons for attending advanced practitioner services and hence identified a niche for these practitioners:

I trusted her because she knows what she's talking about [...] She's a non-confrontational person, you could tell that and [...] because she told me she had a good relationship with him [my general practitioner], I never thought anything of it. I trusted her. I mean, I trust my doctor but, in all honesty, I'd go to her any day, over my doctor. - Patient/carer 7

On the other hand, health professionals interviewed in this study more commonly indicated the inherent uncertainty within the health system over the nurse practitioner and pharmacist prescriber roles. General practitioners who were not working with pharmacist prescribers were almost unanimously unfamiliar with this role. In practice, participants explained that this influenced workplace responsiveness towards the introduction of new roles:

When I first started as a nurse practitioner, I went to a rest home. The rest home had auditors in for their certification and the auditor told me that I couldn't diagnose. I said "Really? It specifically says as part of what a nurse practitioner is, is able to diagnose" [...] Like ordering x-rays, I was rung [...] and they declined my x-ray for a fracture - only doctors can refer for x-rays. Actually, no. - Nurse practitioner 4

Our evaluation of the development of these complex programmes supports the work of Schober et al. (2016) who state that the development of advanced nursing policy proceeds through multiple stages and that a coordinated plan for implementation is required. Broadly, this research considers the development of advanced practitioner roles as a process, beginning with policy creating advanced practitioner roles, and ending with role implementation.

\section{Discussion}

Successful role development does not simply result from an action taken at only one point in time. Stakeholders at different parts of the development pathway must contribute at different times for there to be effective embedding of new health care roles. These include policy and training stakeholders, but also patients and health care providers. Our study has
Developing advanced practitioner roles 
JHOM

33,1

suggested a lack of alignment between policy intent in creating advanced practitioner roles, and the in-practice role realisation and delivery of health services. Where mechanisms in policy and practice are not triggered, development of these roles will not occur as successfully. In turn, this points to a need to consider how best to align role intent with the needs of the health system in its current form. Further research is required to evaluate the development of these practitioners, particularly considering the introduction of additional expanded practice roles (such as registered nurse prescribers) in the New Zealand health system. There is also a need for the long-term monitoring of clinical and economic outcomes to determine the contribution these practitioners make to the delivery of quality health care.

This study adds to the current body of knowledge on advanced practitioner role development, and more broadly, it adds to an understanding of health workforce changes, and to the use of the realist methodology in evaluating the development of complex programmes. This realist analysis suggests that advanced practitioner development efforts are likely to meet with success when the following mechanisms trigger across both policy and practice:

- engagement in planning and integrating roles;

- establishing opportunities as part of a well-defined career pathway; and

- championing role uptake and work to full scopes of practice.

\section{Mechanism 1}

A major challenge to the success of these programmes is to recognise and match the intended role of nurse practitioners and pharmacist prescribers and the niche that they are to fill. In New Zealand, nurse practitioner and pharmacist prescriber are legislatively protected titles. Yet, internationally, several studies have reported concerns around role definitions for nurse practitioners (Marsden et al., 2003; DiCenso and Matthews, 2005; Sangster-Gormley et al., 2011; Contandriopoulos et al., 2015; Donald et al., 2010) and for pharmacist prescribers (Clinical Advisory Pharmacists Association, 2015; McCann et al., 2012; Schindel et al., 2017). DiCenso and Matthews (2005) and Courtenay et al. (2011) demonstrate that appropriate role definitions are needed to prevent role confusion and issues with role implementation and deployment. In New Zealand, based on our research, ways to reduce role confusion include defining universal core competencies of all health professionals working in primary health care, and then establishing system-wide monitoring and evaluation frameworks to determine the value-add of the nurse practitioner and pharmacist prescriber roles.

\section{Mechanism 2}

These new roles require training and experience; participants described challenges related to taking on advanced roles and gaining necessary skills. The need for pre-existing working relationships in negotiating entry to advanced practitioner pathways (Spence and Anderson, 2007; Tann et al., 2010; Weiss et al., 2006) and access to relevant continuing education opportunities is documented in the literature (Carey and Courtenay, 2010; Courtenay et al., 2007; Stewart et al., 2009) describing key conditions for programme success. Individuals operating in environments where education fails to create fit for purpose practitioners are unlikely to develop their roles effectively as they lack opportunities available through well-defined career pathways. From our research, we recommend that postgraduate health education funding become profession agnostic and based instead on the skill needs of the health system. Furthermore, we recommend greater coordination of New Zealand undergraduate health professional training to enable recognition of nursing and pharmacy skill bases by other members of future health care teams. 
Mechanism 3

The national context for establishing these new roles is set by government strategic direction, and professional bodies. With the introduction of the refreshed 2016 New Zealand Health Strategy (Minister of Health, 2016a, b), questions have been raised over the value the Ministry of Health attaches to the pharmacist prescriber role. The questions were raised after statements present in earlier Strategy drafts supporting pharmacist prescriber role creation were removed in the final version (Norton, 2016). No specific comments surrounding the nurse practitioner role were made in this Strategy. The 2001 New Zealand Primary Health Care Strategy guides the New Zealand Government's strategic direction on primary health care (King, 2001). The Strategy identified nursing as a crucial part of the solution for improving population-focused health care delivery. As part of this, the Primary Health Care Strategy recognised the need to set educational and career frameworks to facilitate primary health care nursing expansion. This has met with variable success. Historically, the introduction of nurse practitioners has been influenced by disagreements within nursing regarding advanced nursing qualifications (Jacobs, 2005; Ministerial Taskforce on Nursing, 1998; Wilkinson, 2008). More recently, with the introduction of the pharmacist prescriber, several interviewees questioned whether the pharmacy profession itself was supportive of this expanded practice.

In practice, advanced practitioner role development is influenced by workplace and greater health system contexts. Several nurse practitioners highlighted the need for support from within their own workplace in instances where their patient referrals were not accepted by external agencies, such as hospitals or diagnostic services. Nursing and pharmacy literature offer perspective on this, in terms of how lack of critical mass and recognition of new roles reduces dialogue at practice levels and reduces the ability to use advanced practitioner services (Bradley et al., 2007; Sangster-Gormley et al., 2013; Latter et al., 2011). From our research, we recognise that in New Zealand critical mass of nurse practitioner and pharmacist prescriber roles has likely not been achieved. There is a need for promotion of these roles in both policy and practice environments.

\section{Touching on context}

The development of nurse practitioner and pharmacist prescriber programmes occurs in a complex and quickly evolving system, with multiple other programmes competing for resources. The ability for mechanisms to trigger is dependent on many contexts. As suggested in Figure 2, and touched on in the above discussion, some of these contexts include a responsive health system with enabling policy and legislation, a critical mass of advanced practitioners and recognition of NP and PP roles. In any one environment, some of these contexts will exist, and others not. Similarly, as this research found, some of these contexts may exist in one form, but changes in that context may fail to keep pace with requirements of developing a new role into a legacy system. An example of this is changes in legislation governing advanced practitioner practice boundaries. Contexts will trigger none, one, two or all of the above mechanisms. This will lead to variation in the extent to which successful development occurs.

\section{Methodological considerations}

Since all conclusions are contextual, limitations to the realist approach broadly relate to problems in result reproducibility and generalisability (Pawson et al., 2004, 2005), a problem not limited to realist methodologies. Pawson (2002) elaborates that programme complexity and differences in context mean that a programme, effective in one environment, may fail in another. Future programmes may not evolve in the same manner as current programmes. Similarly, existing programmes, which run within complex, real-world circumstances, evolve due to unobserved and unobservable features. This paper, while able to offer theories
Developing advanced practitioner roles 
JHOM

33,1

of how advanced practitioner role change currently occurs in New Zealand primary health care, may not be directly applicable to programmes operating in different circumstances. However, the theories generated in this study offer insights of value for future programmes that bear a "family resemblance" to the evaluated programmes. Pawson and Tilley (2004) argue that although realist research does not explore all eventualities, it does allow for greater mastery of theories explaining the programme under study. Thus, this research does not intend to confirm causative relationships, but rather it offers insights and greater confidence in patterns of advanced practitioner change across different primary health care practices and the health system. This is pertinent to both policy and practice perspectives.

\section{Conclusions}

This research provides transferable lessons to the development of future practitioner roles. In presenting mechanisms that when triggered lead to successful advanced practitioner development, we highlight the importance of considering the development of these roles during both policy and practice stages. Much of the process as it has occurred in New Zealand fails to link these stages together. Consequently, the realisation and delivery of these roles have failed to meet initial expectations around role creation.

This paper provides an important example of the use of realist methodologies in the evaluation of multiple complex programmes from initial policy conception to operation in practice. Evaluating changes in workforce development with the introduction of new health professional roles requires respect for the complex and evolving nature of these programmes. Evaluation methodologies are required that foster an explanation of not only whether a programme works, but also how it works. A realist methodology provides useful tools to understand how advanced practitioner development occurs through exploring the effect of contexts and mechanisms on programme success.

\section{References}

Bissell, P., Cooper, R., Guillaume, L., Anderson, C., Avery, A., Hutchinson, A., James, V., Lymn, J., Marsden, E., Murphy, E., Ratcliffe, J., Ward, P. and Woolsey, I. (2008), An Evaluation of Supplementary Prescribing in Nursing and Pharmacy, Department of Health, London.

Blamey, A. and Mackenzie, M. (2007), "Theories of change and realistic evaluation: peas in a pod or apples and oranges?", Evaluation, Vol. 13 No. 4, pp. 439-455.

Bradley, E., Hynam, B. and Nolan, P. (2007), "Nurse prescribing: reflections on safety in practice", Social Science \& Medicine, Vol. 65 No. 3, pp. 599-609.

Bryant-Lukosius, D. and DiCenso, A. (2004), "A framework for the introduction and evaluation of advanced practice nursing roles”, Journal of Advanced Nursing, Vol. 48 No. 5, pp. 530-540.

Byng, R., Norman, I. and Redfern, S. (2005), "Using realistic evaluation to evaluate a practice-level intervention to improve primary healthcare for patients with long-term mental illness", Evaluation, Vol. 11 No. 1, pp. 69-93.

Carey, N. and Courtenay, M. (2010), "An exploration of the continuing professional development needs of nurse independent prescribers and nurse supplementary prescribers who prescribe medicines for patients with diabetes", Journal of Clinical Nursing, Vol. 19 Nos 1-2, pp. 208-216.

Clinical Advisory Pharmacists Association (2015), "Pharmacist prescribers' workshop - notes", paper presented at Pharmacist Prescribers' Workshop, Wellington, 21 November, available at: http://capanz.org (accessed 18 January 2016).

Contandriopoulos, D., Brousselle, A., Dubois, C.-A., Perroux, M., Beaulieu, M.-D., Brault, I., Kilpatrick, K., D'Amour, D. and Sansgter-Gormley, E. (2015), "A process-based framework to guide nurse practitioners integration into primary healthcare teams: results from a logic analysis", BMC Health Services Research, Vol. 15 No. 1, p. 78. 
Courtenay, M., Carey, N. and Burke, J. (2007), "Independent extended and supplementary nurse prescribing practice in the UK: a national questionnaire survey", International Journal of Nursing Studies, Vol. 44 No. 7, pp. 1093-1101.

Courtenay, M., Carey, N. and Stenner, K. (2011), "Non medical prescribing leads views on their role and the implementation of non medical prescribing from a multi-organisational perspective", BMC Health Services Research, Vol. 11 No. 1, p. 142.

De Geest, S., Moons, P., Callens, B., Gut, C., Lindpaintner, L. and Spirig, R. (2008), "Introducing advanced practice nurses/nurse practitioners in health care systems: a framework for reflection and analysis", Swiss Medical Weekly, Vol. 138 Nos 43-44, pp. 621-628.

DiCenso, A. and Matthews, S. (2005), "Report on the integration of primary health care nurse practitioners into the province of Ontario", Ministry of Health and Long-Term Care, Ontario, January.

Donald, F., Bryant-Lukosius, D., Martin-Misener, R., Kaasalainen, S., Kilpatrick, K., Carter, N., Harbman, P., Bourgeault, I. and DiCenso, A. (2010), "Clinical nurse specialists and nurse practitioners: title confusion and lack of role clarity", Nursing Leadership, Vol. 23, Special Issue, pp. 189-210.

Emmerton, L., Marriott, J., Bessell, T., Nissen, L. and Dean, L. (2005), "Pharmacists and prescribing rights: review of international developments", Journal of Pharmacy \& Pharmaceutical Sciences, Vol. 8 No. 2, pp. 217-225.

Horrocks, S., Anderson, E. and Salisbury, C. (2002), "Systematic review of whether nurse practitioners working in primary care can provide equivalent care to doctors", British Medical Journal, Vol. 324, pp. 819-823.

Hughes, F. and Carryer, J. (2002), Nurse Practitioners in New Zealand, Ministry of Health, Wellington.

Jacobs, S.H. (2005), "Advanced nursing practice and the nurse practitioner: New Zealand nursing's professional project in the late 20th century", doctoral thesis, Massey University, Palmerston North.

King, A. (2001), The Primary Health Care Strategy, Ministry of Health, Wellington.

Latter, S., Blenkinsopp, A., Smith, A., Chapman, S., Tinelli, M., Gerard, K., Little, P., Celino, N., Granby, T., Nicholls, P. and Dorer, G. (2011), Evaluation of Nurse and Pharmacist Independent Prescribing, University of Southampton Keele University on behalf of Department of Health, Southampton.

Laurant, M., Harmsen, M., Wollersheim, H., Grol, R., Faber, M. and Sibbald, B. (2009), "The impact of nonphysician clinicians: do they improve the quality and cost-effectiveness of health care services?", Medical Care Research and Review, Vol. 66 No. S6, pp. 36S-89S.

McCann, L., Lloyd, F., Parsons, C., Gormley, G., Haughey, S., Crealey, G. and Hughes, C.M. (2012), "They come with multiple morbidities': a qualitative assessment of pharmacist prescribing", Journal of Interprofessional Care, Vol. 26 No. 2, pp. 127-133.

Manzano, A. (2016), "The craft of interviewing in realist evaluation", Evaluation, Vol. 22 No. 3, pp. 342-360.

Marchal, B., van Belle, S., van Olmen, J., Hoerée, T. and Kegels, G. (2012), "Is realist evaluation keeping its promise? A review of published empirical studies in the field of health systems research", Evaluation, Vol. 18 No. 2, pp. 192-212.

Marsden, J., Dolan, B. and Holt, L. (2003), "Nurse practitioner practice and deployment: electronic mail Delphi study", Journal of Advanced Nursing, Vol. 43 No. 6, pp. 595-605.

Martin-Misener, R., Downe-Wamboldt, B., Cain, E. and Girouard, M. (2009), "Cost effectiveness and outcomes of a nurse practitioner-paramedic-family physician model of care: the long and brier islands study", Primary Health Care Research \& Development, Vol. 10 No. 1, pp. 14-25.

Merton, R.K. (2007), "On sociological theories of the middle range [1949]", in Calhoun, C., Gerteis, J., Moody, J., Pfaff, S. and Virk, I. (Eds), Classical Sociological Theory, 2nd ed., Blackwell Publishing, Malden, MA, pp. 448-459. 
JHOM

33,1

Minister of Health (2016a), "New Zealand health strategy: future direction”, Ministry of Health, Wellington.

Minister of Health (2016b), "New Zealand health strategy: roadmap of actions 2016", Ministry of Health, Wellington.

Ministerial Taskforce on Nursing (1998), "Report of the ministerial taskforce on nursing: releasing the potential of nursing", Ministry of Health, Wellington, August.

Ministry of Health (2012), "Social policy committee cabinet paper on designated prescribing rights for pharmacist prescribers", Health report, Ministry of Health, Wellington, November.

Ministry of Health (2017), "Pharmacist prescriber", Ministry of Health, Wellington, available at: www. health.govt.nz/our-work/health-workforce/new-roles-and-initiatives/established-initiatives/ pharmacist-prescriber (accessed 28 September 2017).

Norton, M. (2016), "Health minister launches health strategy, leaves out pharmacy prescribing", Pharmacy Today, 18 April.

Nursing Council of New Zealand (2017a), "2017 annual report: for the year ended 31 March", annual report, Nursing Council of New Zealand, Wellington.

Nursing Council of New Zealand (2017b), "Nurse prescribing: registered nurse prescribing", available at: www.nursingcouncil.org.nz/Nurses/Nurse-Prescribing (accessed 28 September 2017).

Patton, M.Q. (2002), Qualitative Evaluation and Research Methods, SAGE Publications, Thousand Oaks, CA.

Pawson, R. (1996), “Theorizing the interview”, The British Journal of Sociology, Vol. 47 No. 2, pp. 295-314.

Pawson, R. (2002), "Evidence-based policy: the promise of 'realist synthesis'”, Evaluation, Vol. 8 No. 3, pp. 340-358.

Pawson, R. (2006), Evidence-Based Policy: A Realist Perspective, SAGE Publications, London.

Pawson, R. (2013), The Science of Evaluation: A Realist Manifesto, SAGE Publications, London.

Pawson, R. and Tilley, N. (1997), Realistic Evaluation, SAGE Publications, London.

Pawson, R. and Tilley, N. (2001), "Realistic evaluation bloodlines", American Journal of Evaluation, Vol. 22 No. 3, pp. 317-324.

Pawson, R. and Tilley, N. (2004), "Realist evaluation", British Cabinet Office, available at: www. communitymatters.com.au/RE_chapter.pdf (accessed 1 December 2017).

Pawson, R., Greenhalgh, T., Harvey, G. and Walshe, K. (2004), "Realist synthesis: an introduction”, Research Methods: An ESRC Research Programme, working paper series, University of Manchester, August.

Pawson, R., Greenhalgh, T., Harvey, G. and Walshe, K. (2005), "Realist review - a new method of systematic review designed for complex policy interventions", Journal of Health Services Research \& Policy, Vol. 10 No. 1, pp. 21-34.

Pharmacy Council of New Zealand (2010), Application For Consideration of Independent Prescribing Rights: Pharmacist Prescriber Scope of Practice, Pharmacy Council of New Zealand, Wellington.

Piper, D. (2014), "Viability of pharmacist prescribers in doubt", Pharmacy Today, May.

Sangster-Gormley, E., Martin-Misener, R. and Burge, F. (2013), "A case study of nurse practitioner role implementation in primary care: what happens when new roles are introduced?", BMC Nursing, Vol. 12 No. 1.

Sangster-Gormley, E., Martin-Misener, R., Downe-Wamboldt, B. and Dicenso, A. (2011), "Factors affecting nurse practitioner role implementation in Canadian practice settings: an integrative review”, Journal of Advanced Nursing, Vol. 67 No. 6, pp. 1178-1190.

Schindel, T.J., Yuksel, N., Breault, R., Daniels, J., Varnhagen, S. and Hughes, C.A. (2017), "Perceptions of pharmacists' roles in the era of expanding scopes of practice", Research in Social and Administrative Pharmacy, Vol. 13 No. 1, pp. 148-161.

Schober, M.M., Gerrish, K. and McDonnell, A. (2016), "Development of a conceptual policy framework for advanced practice nursing: an ethnographic study", Journal of Advanced Nursing, Vol. 72 No. 6, pp. 1313-1324. 
Sibbald, B., Shen, J. and McBride, A. (2004), "Changing the skill-mix of the health care workforce", Journal of Health Services Research \& Policy, Vol. 9 No. S1, pp. 28-38.

Spence, D. and Anderson, M. (2007), "Implementing a prescribing practicum within a master's degree in advanced nursing practice”, Nursing Praxis in New Zealand, Vol. 23 No. 2, pp. 27-42.

Stewart, D., George, J., Bond, C.M., Diack, H.L., McCaig, D.J. and Cunningham, S. (2009), "Views of pharmacist prescribers, doctors and patients on pharmacist prescribing implementation", International Journal of Pharmacy Practice, Vol. 17 No. 2, pp. 89-94.

Tann, J., Blenkinsopp, A., Grime, J. and Evans, A. (2010), "The great boundary crossing: perceptions on training pharmacists as supplementary prescribers in the UK”, Health Education Journal, Vol. 69 No. 2, pp. 183-191.

Thomas, F. (2017), "Nurse practitioners going to waste in culture of confusion and mistrust", New Zealand Doctor, 13 June.

Vaessen, J. and Leeuw, F.L. (2011), Mind The Gap: Perspectives on Policy Evaluation and the Social Sciences, Transaction Publishers, New Brunswick, NJ.

Weiss, M.C., Sutton, J. and Adams, C. (2006), Exploring Innovation in Pharmacy Practice: A Qualitative Evaluation of Supplementary Prescribing By Pharmacists, Royal Pharmaceutical Society of Great Britain, London.

Wilkinson, J. (2008), “The ministerial taskforce on nursing: a struggle for control”, Nursing Praxis in New Zealand, Vol. 24 No. 3, pp. 5-16.

Wong, G., Greenhalgh, T., Westhorp, G., Buckingham, J. and Pawson, R. (2013), "RAMESES publication standards: realist syntheses”, BMC Medicine, Vol. 11 No. 1.

\section{Corresponding author}

Tara Officer can be contacted at: tara.officer@vuw.ac.nz
Developing advanced practitioner roles

For instructions on how to order reprints of this article, please visit our website: 